\title{
A comprehensive model to address reproductive health and family planning needs of factory workers in Port Said
}

Evidence Project

Follow this and additional works at: https://knowledgecommons.popcouncil.org/departments_sbsr-rh How does access to this work benefit you? Let us know!

\section{Recommended Citation}

Evidence Project. 2021. "A comprehensive model to address reproductive health and family planning needs of factory workers in Port Said," infographic. Washington, DC: Population Council, The Evidence Project. 


\section{A Comprehensive Model to Address Reproductive Health and Family Planning Needs of Factory Workers in Port Said}

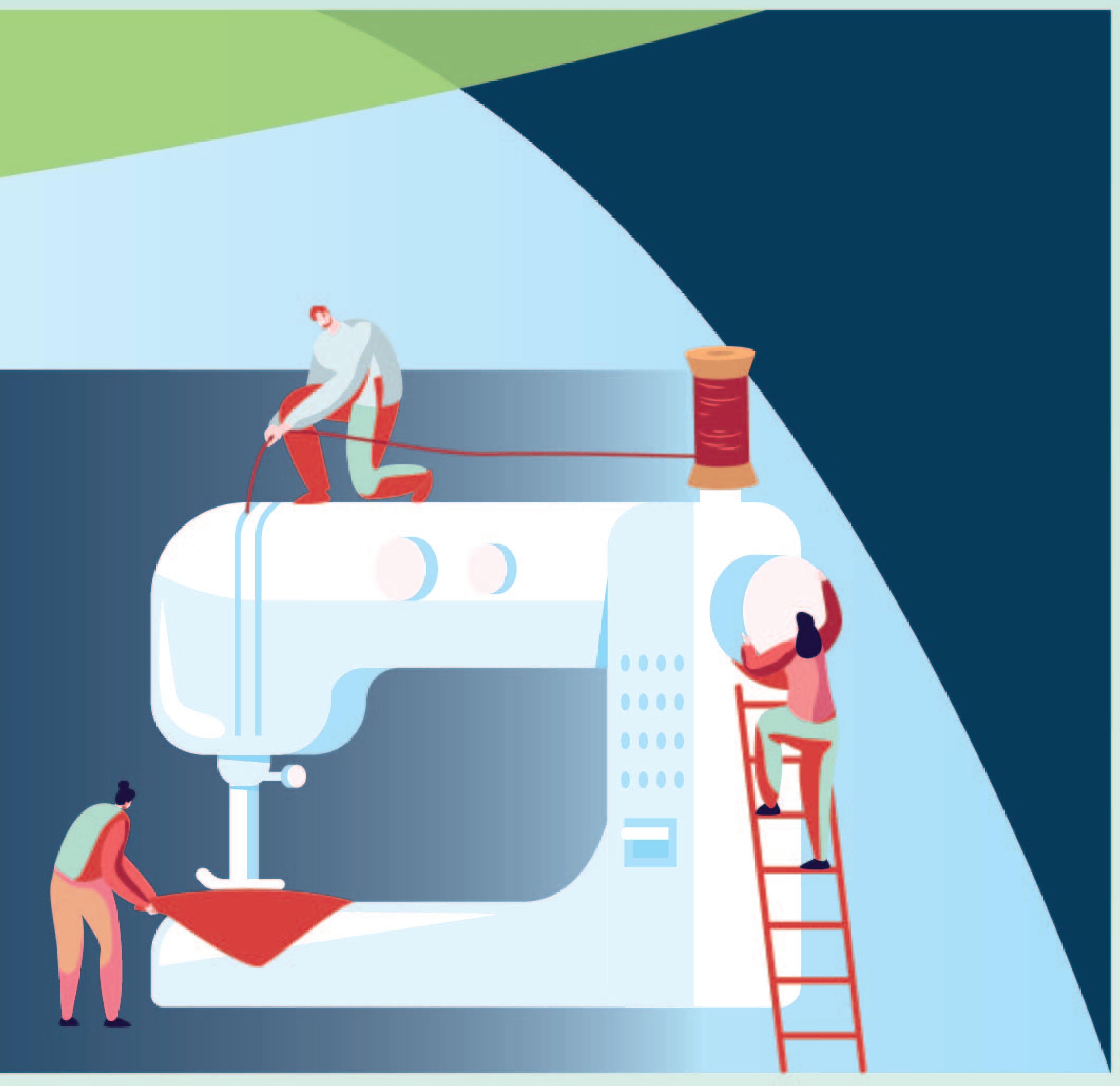

Goal: To increase demand for private family planning/reproductive health (FP/RH) services among young male and female garment factory workers (18-35 years) in Port Said's Investment Zone.'

\section{Intervention}
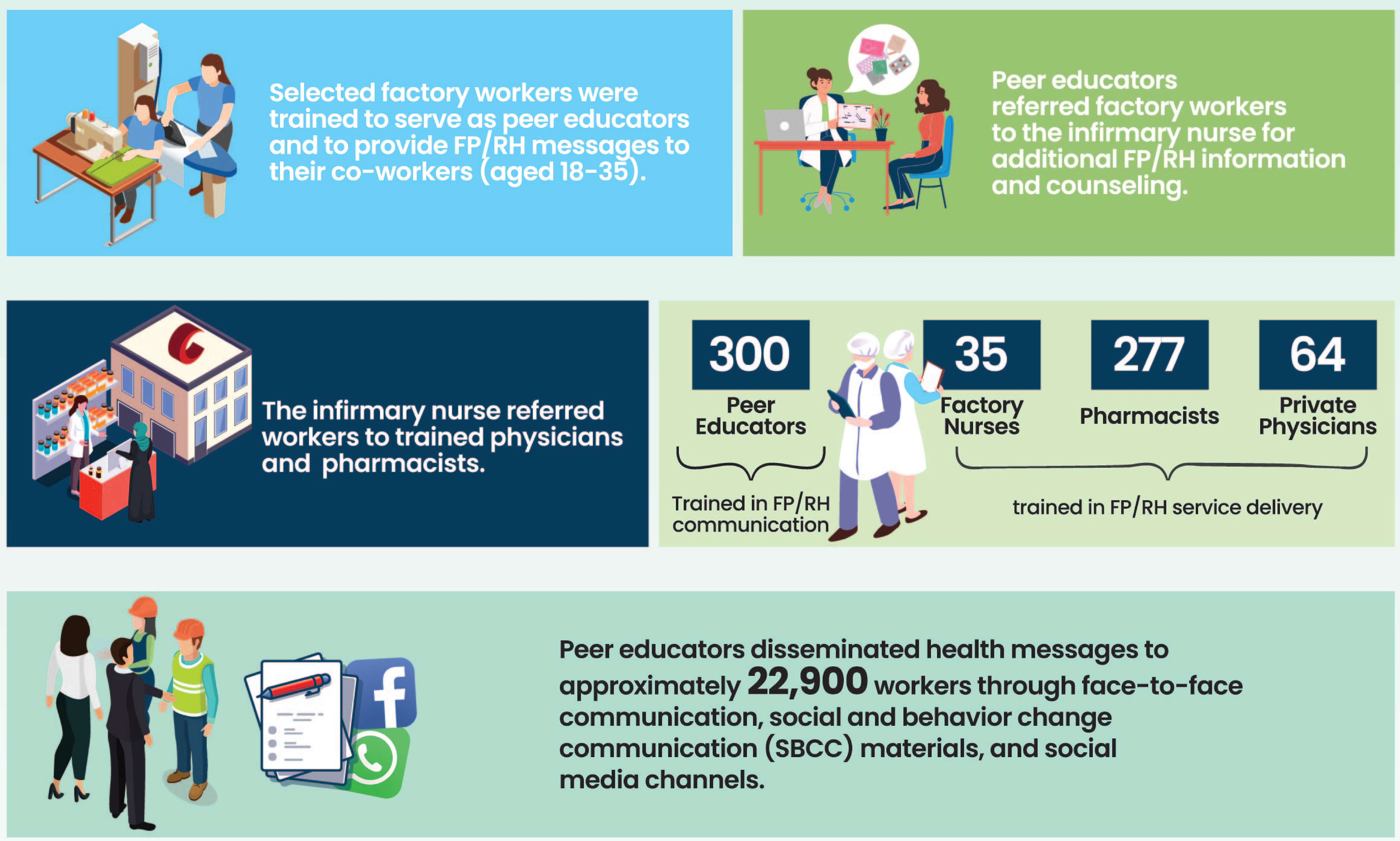

Peer educators disseminated health messages to approximately 22,900 workers through face-to-face communication, social and behavior change communication (SBCC) materials, and social media channels. 


\section{Participants' Perspectives ${ }^{2}$}
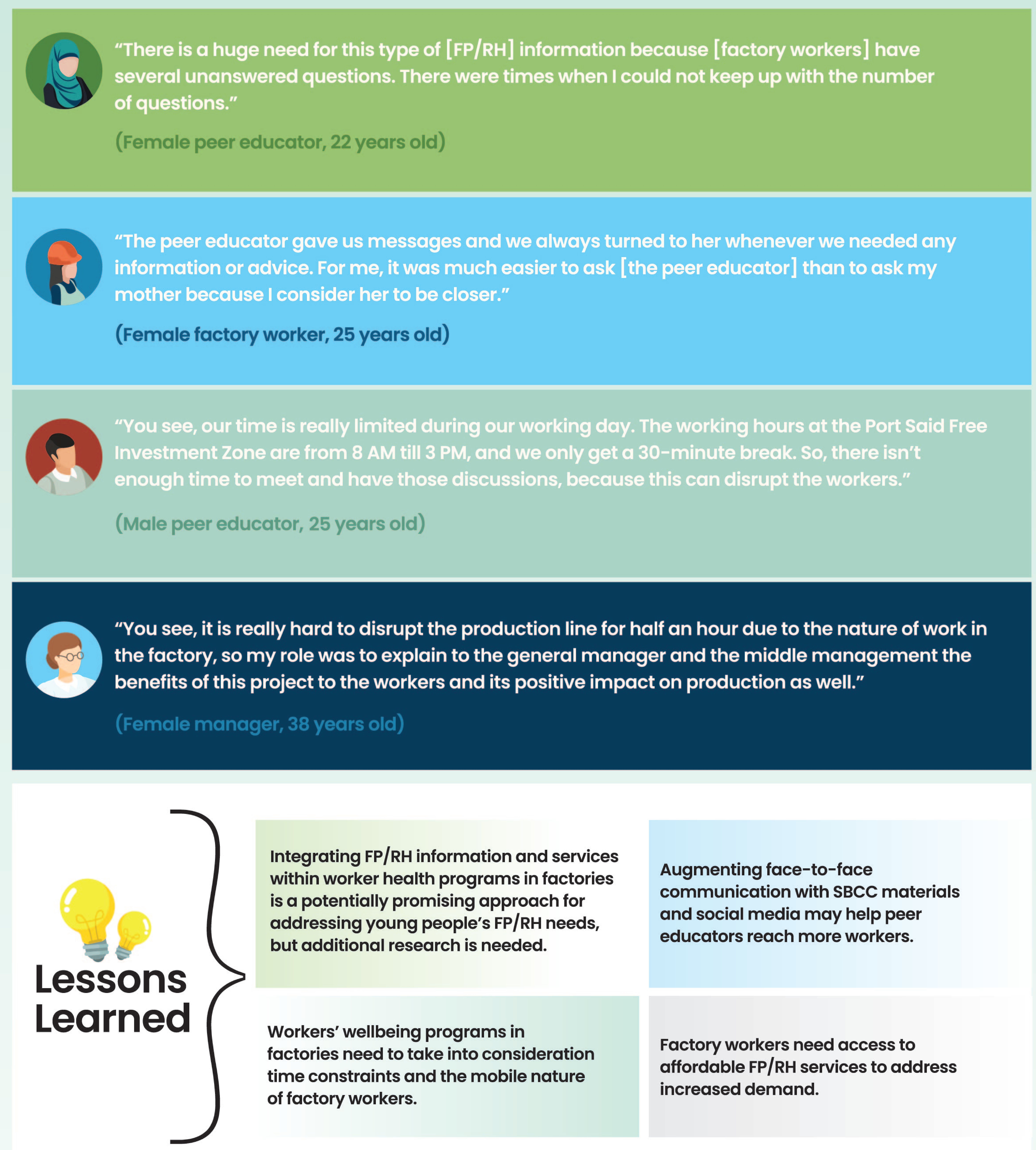

Integrating FP/RH information and services within worker health programs in factories is a potentially promising approach for addressing young people's FP/RH needs, but additional research is needed.

Workers' wellbeing programs in factories need to take into consideration time constraints and the mobile nature of factory workers.
Augmenting face-to-face communication with SBCC materials and social media may help peer educators reach more workers.

Factory workers need access to affordable FP/RH services to address increased demand.

2 To learn more about the effects of the intervention on young people's knowledge, attitudes and practices regarding family planning, please check: Abdel-Tawab, Nahla, Norhan Bader, Elizabeth Tobey, and Aparna Jain. 2020. “Two implementation models of workers' health education programs in Egypt: What works? What doesn't work?" Research Brief. Washington DC: Population Council, The Evidence Project.

USAID $\begin{aligned} & \text { The Evidence Project is made possible by the generous support of the American people through the United States Agency for International Development (USAID) under the } \\ & \text { terms of cooperative agreement no. AID-OAA-A-13-00087. The contents of this document are the sole responsibility of the Evidence Project and the Population Council } \\ & \text { and do not necessarily reflect the views of USAID or the United States Government. }\end{aligned}$
$\begin{aligned} & \text { Evidence Evidence Project uses implementation science-the strategic generation, translation, and use of evidence-to strengthen and scale up family planning and reproductive } \\ & \text { health programs to reduce unintended pregnancies worldwide. The Evidence Project is led by the Population Council. } \\ & \text { (c) 2021, The Population Council, Inc. }\end{aligned}$

